\title{
The Effect of Clinical Pathway in Patients with Acute Complicated Appendicitis
}

\author{
Can Guo, Zhonghui Zou* \\ Department of General Surgery, Chongqing Three Gorges Central Hospital, Chongqing, China \\ Email: zouzhonghui97@163.com
}

Received 7 June 2016; accepted 2 July 2016; published 5 July 2016

Copyright (C) 2016 by authors and Scientific Research Publishing Inc.

This work is licensed under the Creative Commons Attribution International License (CC BY). http://creativecommons.org/licenses/by/4.0/

(c) () Op Open Access

\begin{abstract}
Clinical pathway (CP) is a medical management tool made by a group of medical specialists and specialized for certain diseases. It has been proved that CP was an efficient way to optimize the hospitalization management and control medical cost. In this paper, we focused on the effect of CP in the patients with acute complicated appendicitis via total duration of hospitalization, hospitalization time before operation, total cost of hospitalization and drug expenditure. From March 2014 to March 2015, the patients with conditions of appendicitis in Three Gorges Central Hospital of Wanzhou, Chongqing, were divided into CP group and non path control group to analyze the effect of the application of CP. Our data showed that there were no significant differences between two groups of patients in total duration of hospitalization, hospitalization time before operation, total cost of hospitalization and drug expenditure. The implementation of CP neither decreased the time of patients in hospital nor the total hospitalization cost. Besides, application of CP for acute appendicitis patients should distinguish between simple appendicitis and complicated appendicitis, simple appendectomy patients implement $\mathrm{CP}$ is beneficial, and patients with complicated appendicitis did not come from the benefit.
\end{abstract}

\section{Keywords}

Clinical Pathway, Appendicitis, Effect Analysis

\section{Introduction}

Clinical pathways, also known as care pathways, critical pathways, integrated care pathways, or care maps, are one of the main tools used to manage the quality in healthcare concerning the standardization of care processes. It has been intensively applied in many hospitals all over the world because of its benefits in the medical quality

*Corresponding author. 
improvement, hospitalization cost control and optimization of medical service [1]. In 2009, Chinese Ministry of Heath started to develop CP in whole China and CP council was set up to develop CP standards in 22 medical majors including 122 kinds of certain diseases. Especially, in general surgery department, CP was made for acute simple appendicitis. Generally speaking, the clinical pathway and standardizing treatment protocol for acute appendicitis is thought to be difficult to adopt because this disease shows various clinical patterns according to the degree of inflammation. Its diagnosis is sometimes difficult even for an experienced doctor when, because of disease progression, the classical clinical picture is absent and surgical decision-making poses a challenge. Delay in diagnosis and timing of surgery may further complicate the course of the disease, which will result in a longer hospital stay and high hospital costs in some cases. However, acute appendicitis is one of most common surgical diseases and therefore, a simple and precise medical protocol with a clinical pathway would be necessary to improve the treatment outcome and patient satisfaction [2] [3]. Besides, the number of acute simple appendicitis cases is relatively small in clinic stage by comparison with acute complicated appendicitis, which includes suppurative appendicitis, gangrenous appendicitis and gangrenous appendicitis with perforation [4] [5]. In this paper, we focused on the effect of $\mathrm{CP}$ in the patients with acute complicated appendicitis. By comparing total duration of hospitalization, hospitalization time before operation, total cost of hospitalization and drug expenditure in $\mathrm{CP}$ and non-CP patients, we tried to find out in situ questions of CP in patients with acute complicated appendicitis and come up with the proper solution in clinical treatment.

\section{Material and Methods}

\subsection{Patients and Methods}

There was no ethical conflict with this research, all patients were informed before our calculation. Total 684 patients with conditions of appendicitis in Three Gorges Central Hospital of Wanzhou, Chongqing were included in this research, over a period of two years between March 2014 and March 2015. Although there is no diagnostic gold-standard for appendicitis, all patients presented with abdominal pain and suspicion of appendicitis based on initial evaluation by ED physician and then diagnosed by PAS method. All patients were randomly divided into two groups: CP and non-CP management. CP group included 358 patients, in which male 185 and female 173 , age from $14-71$ and the average age was 45 . Non-CP group included 326 patients, in which male 171 and female 155, age from 14 - 69 and the average age was 48 . All patients were evaluated by history and clinical examination, there were no significant differences in age and gender between two groups $(\mathrm{p}>0.05)$.

\subsection{Clinical Pathway Management}

A surgery multidisciplinary team, consisting of general hospital-based physicians, pulmonologists, emergency medicine physicians, outpatient physicians, clinical nurses, social workers, and other members of our surgery care team participated actively in the design of clinical pathway. The clinical pathway was designed for patients, who were being admitted to the hospital with a primary diagnosis of appendicitis. Patients meeting these criteria and whose families had a phone or pager were eligible for the study. Patients admitted to the intensive care unit and patients who had previously been enrolled in the study were excluded. Study enrollment also required that inpatient beds be available in both our intervention and control sites at the time of admission, so that randomization could take place. After all, total duration of hospitalization, hospitalization time before operation, total cost of hospitalization and drug expenditure were evaluated between CP and non-CP group.

\subsection{Operation Process}

A McBurney's interlacing incision was made to enter the peritoneum. The stump of the appendix was inverted into the cecum with a purse-string suture in the usual manner. After confirming that there was no pus-like fluid in Douglas' pouch or the right paracolic cavity, the peritoneum was closed with absorbable thread. The subcutaneous tissue and skin were closed with 3-0 Vicryl, 4-0 monocryl, and Dermabond. No drain was inserted. When the patient had perforation or abscess, a Lennander's pararectus incision was made and the appendix was removed as described. A closed drainage tube was inserted in Douglas' pouch and the right paracolic cavity and a Penrose drainage tube was left in the subcutaneous tissue. Primary skin closure was performed with interrupted 3-0 silk suture. 


\subsection{Medication}

All patients were divided into two groups and given two doses of intravenous antibiotics postoperatively followed by 3 days of oral antibiotics. A: Ceftriaxone Sodium $(0.2 \mathrm{~g})+$ Tinidazole $(0.4 \mathrm{~g})$ with average medication time (5.00 \pm 0.83$)$ days; B: Ceftazidime ( $2.0 \mathrm{~g})+$ Tinidazole $(0.4 \mathrm{~g})$ with average medication time (5.32 \pm 1.05$)$ days.

\subsection{Statistics}

Statistical measurements were performed by SPSS 13.0 software and the results were presented by $\bar{X} \pm \mathrm{S}$. We studied each quantitative variable using the Student's t-test, and each qualitative variable using the $\chi^{2}$ test. We considered $\mathrm{p}$ values $<0.05$ significant.

\section{Results}

There were 358 patients in the CP group and 326 in the control group. The diagnosis of appendicitis was confirmed histopathologically in all the patients who underwent appendectomy.

The patient demographics, history of previous abdominal surgery, and operative findings were similar in the control and CP groups. The mean age of was 48 years in the control group and 45 years in the CP group. There were no significant differences between the groups.

The mean length of hospitalization in CP group was $7 \pm 0.58$ days, which was not significantly different with control group $7 \pm 0.83$ days ( $p>0.05$ ). Besides, CP management did not show positive effect in decreasing the postoperative stay of patients with acute complicated appendicitis. The mean postoperative stay of CP group was $5 \pm 0.64$ days, which was not significantly different from control group with $5 \pm 0.49$ days. Furthermore, the recovery rate of the patients in each group was nearly the same which may indicate that the CP management did not show its advantages in acute complicated appendicitis (Table 1).

There were no significant differences in total hospital costs between CP group and control (8482 \pm 78 vs 8506 $\pm 82, \mathrm{p}=0.25$ ). Besides, CP management did not significantly decrease the total medication costs for patients with acute complicated appendicitis. The mean medication costs in CP group were $2567 \pm 35$ compared with control $2521 \pm 54(\mathrm{p}=0.32>0.05)$ (Table 2).

All patients were divided into two groups and given two doses of intravenous antibiotics postoperatively followed by 3 days of oral antibiotics. Our data showed that these two patterns of intravenous antibiotics both worked great in patients with acute complicated appendicitis, there were no significant differences between two patterns of intravenous antibiotics (Table 3, Table 4).

\section{Discussion}

The clinical pathway has become widely adopted in China since its introduction by Chinese Ministry of Heath, and has been under trial in several hospitals since 2009. In making a clinical pathway, the treatment of a particular

Table 1. Mean length of hospitalization, postoperative stay and recovery rate in each group.

\begin{tabular}{ccccc}
\hline Group & Cases & Mean length of hospitalization (d) & Postoperative stay (d) & Recovery rate \% \\
\hline CP & 358 & $7 \pm 0.58$ & $5 \pm 0.64$ & $88 \pm 0.97$ \\
Control & 326 & $7 \pm 0.83$ & $5 \pm 0.49$ & $87 \pm 0.56$ \\
\hline
\end{tabular}

Mean length of hospitalization: $\mathrm{p}=0.35>0.05$, no significant differences. Postoperative stay: $\mathrm{p}=0.35>0.05$, no significant differences. Recovery rate: $\mathrm{p}=0.39>0.05$, no significant differences.

Table 2. Hospital costs and medication costs in each group.

\begin{tabular}{cccc}
\hline Group & Cases & Hospital costs (¥) & Medication cost (¥) \\
\hline CP & 358 & $8482 \pm 78$ & $2567 \pm 35$ \\
Control & 326 & $8506 \pm 82$ & $2521 \pm 54$ \\
\hline
\end{tabular}

Hospital costs: $\mathrm{p}=0.25>0.05$, no significant differences. Medication cost: $\mathrm{p}=0.32>0.05$, no significant differences. 
Table 3. Effect of two patterns intravenous antibiotics in control group.

\begin{tabular}{ccccc}
\hline Group & Cases & recovery & effective & invalid \\
\hline A & 170 & 148 & 15 & 7 \\
B & 156 & 140 & 11 & 5 \\
\hline
\end{tabular}

$\mathrm{X}^{2}=0.43, \mathrm{p}=0.8>0.05$, no significant differences.

Table 4. effect of two patterns intravenous antibiotics in CP group.

\begin{tabular}{ccccc}
\hline Group & Cases & Recovery & Effective & Invalid \\
A & 180 & 162 & 10 & 7 \\
B & 178 & 158 & 12 & 8 \\
\hline
\end{tabular}

$\mathrm{X}^{2}=0.51, \mathrm{p}=0.65>0.05$, no significant differences.

disease needs to be standardized, but since this is a standard scale, some cases do not follow a predictable course and variance from the pathway is inevitable. Acute appendicitis shows various clinical patterns according to the degree of inflammation, so variance from the pathway for acute appendicitis is a major problem that needs to be solved. Moreover, the number of acute simple appendicitis cases is relatively small in clinic stage by comparison with acute complicated appendicitis, which includes suppurative appendicitis, gangrenous appendicitis and gangrenous appendicitis with perforation [6] [7].

To reduce variance, we classified cases of acute complicated appendicitis into groups. First, cases were classified as those treated surgically. Surgical cases were then divided into two groups, according to whether or not there was perforation or abscess, because perforated appendicitis differs from nonperforated appendicitis in its surgical treatment and use of drains, and is associated with a longer postoperative stay and higher hospital costs. In the postoperative pathway, the criteria for discharge were clarified. Furthermore, by making the treatment protocol and criteria for discharge clear, patients and nurses were able to understand the treatment more clearly, which helped them to accept it. As a result, our clinical pathway and standardization of treatment for acute appendicitis improved the satisfaction of patients and nurses and they were well accepted by both.

In dealing with acute appendicitis, it is sometimes difficult to make a differential diagnosis from other acute abdominal diseases. Some patients are operated on after a few days of conservative therapy without any resolution of symptoms. Some cases progress to perforation and peritonitis when it is difficult to time the operation correctly. Such operations become complicated, resulting in a longer postoperative stay and higher hospital costs. However, because acute appendicitis is one of the most common surgical diseases, reducing hospital costs is of paramount importance [8] [9]. A simple and precise clinical pathway and medical guidelines for treating acute appendicitis would be have a great impact on hospitals, and promote patient satisfaction. There has been much discussion about the operative indications for acute appendicitis. It was traditionally believed that patients with signs of acute appendicitis should undergo surgical exploration, but studies in the 1960s found that if this group of patients was closely observed, about one third recovered without an operation [10]. While it is agreed that perforated appendicitis or appendicitis with an abdominal abscess is an indication for surgery, the surgical indications for nonperforated appendicitis remain controversial. However, some cases do not respond to conservative therapy and the progressive disease process may complicate the course of the disease, resulting in a longer stay and higher hospital costs [11]-[13].

In this paper, we focused on the effect of CP in the patients with acute complicated appendicitis. By comparing total duration of hospitalization, hospitalization time before operation, total cost of hospitalization and drug expenditure in CP and non-CP patients, we tried to find out in situ questions of CP in patients with acute complicated appendicitis and come up with the proper solution in clinical treatment [14] [15].

The research conducted by Warner in 1998, showed that CP could decrease the hospital stay and cost for acute appendicitis [2], which was opposite with our results. This contradiction could be explained with different stage of appendicitis. Warner's data came from the simple acute appendicitis, but in the contrary, we studied on complicated acute appendicitis, which is more complicated in surgery process and prognosis. Our clinical pathway and standardization of treatment for acute complicated appendicitis did not decrease the total length of hospitalization and postoperative stay. Besides, in our study the hospital costs in the CP group were as much as the 
control group. These results show that our clinical pathway and standardization of treatment for acute complicated appendicitis might not be a successful solution to promote the quality of care. Obviously, the results of our studies were limited by relatively small number of patients, in the future, we should consider to extend the scope of this investigation to build a more precise model for CP in acute complicated appendicitis.

\section{Conclusion}

Our clinical pathway and standardization of treatment for acute complicated appendicitis did not decrease the length of hospitalization and costs, application of CP for acute appendicitis patients should distinguish between simple appendicitis and complicated appendicitis, simple appendectomy patients implement CP is beneficial, and patients with complicated appendicitis did not come from the benefit.

\section{Acknowledgements}

This work was financially supported by the Science and technology project of Wanzhou District, Chongqing (No. 201403017).

\section{References}

[1] Cappendijk, V.C. and Hazebroek, F.W. (2000) The Impact of Diagnostic Delay on the Course of Acute Appendicitis. Archives of Diseases in Childhood, 83, 64-66. http://dx.doi.org/10.1136/adc.83.1.64

[2] Warner, B.W., Kulick, R.M., Stoops, M.M., Mehta, S., Stephan, M. and Kotagal, U.R. (1998) An Evidenced-Based Clinical Pathway for Acute Appendicitis Decreases Hospital Duration and Cost. Journal of Pediatrics Surgery, 33, 1371-1375. http://dx.doi.org/10.1016/S0022-3468(98)90010-0

[3] Firilas, A.M., Higginbotham, P.H., Johnson, D.D., Jackson, R.J., Wagner, C.W. and Smith, S.D. (1999) A New Economic Benchmark for Surgical Treatment of Appendicitis. The American Surgeon, 65, 769-773.

[4] Jones, P.F. (2001) Suspected Acute Appendicitis: Trends in Management over 30 Years. British Journal of Surgery, 88, 1570-1577. http://dx.doi.org/10.1046/j.0007-1323.2001.01910.x

[5] Rao, P.M., Rhea, J.T., Novelline, R.A. and McCabe, C.J. (1998) The Computed Tomography Appearance of Recurrent and Chronic Appendicitis. The American Journal of Emergency Medicine, 16, 26-33. http://dx.doi.org/10.1016/S0735-6757(98)90060-2

[6] Savrin, R.A., Clausen, K., Martin Jr., E.W. and Cooperman, M. (1979) Chronic and Recurrent Appendicitis. The American Journal of Surgery, 137, 355-357. http://dx.doi.org/10.1016/0002-9610(79)90066-7

[7] Eriksson, S. and Granstrom, L. (1995) Randomized Controlled Trial of Appendectomy versus Antibiotic Therapy for Acute Appendicitis. British Journal of Surgery, 82, 166-169. http://dx.doi.org/10.1002/bjs.1800820207

[8] Cobben, L.P., de Van Otterloo, A.M. and Puylaert, J.B. (2000) Spontaneously Resolving Appendicitis: Frequency and Natural History in 60 Patients. Radiology, 215, 349-352. http://dx.doi.org/10.1148/radiology.215.2.r00ma08349

[9] McDonald, G.P., Pendarvis, D.P., Wilmoth, R. and Daley, B.J. (2001) Influence of Preoperative Computed Tomography on Patients Undergoing Appendectomy. The American Surgeon, 67, 1017-1021.

[10] Ford, R.D., Passinault, W.J. and Morse, M.E. (1994) Diagnostic ultrasound for suspected appendicitis: does the added cost produce a better outcome? The American Surgeon, 60, 895-898.

[11] Cash, G. and Frazee, R. (2012) Improvements in Laparoscopic Treatment for Complicated Appendicitis. Journal of Laparoendoscopic \& Advanced Surgical Techniques A, 22, 581-583.

[12] Wang, S.M., Huang, F.C., Wu, C.H., et al. (2010) Ileocecal Burkitt’s Lymphoma Presenting as Lleocolic Intussusception with Appendieeal Invagination and Acute Appendicitis. Journal of Formosan Medical Association, 109, 476-479. http://dx.doi.org/10.1016/S0929-6646(10)60080-0

[13] Karaman, A., Cavumglu, Y.H., Karaman, I., et al. (2003) Seven Cases of Neomatal Appendicitis with a Review of the English Language Literature of the Last Century. Pediatric Surgery International, 19, 707-709. http://dx.doi.org/10.1007/s00383-003-1030-5

[14] Lisa, A. and Sanchez, L.A. (1994) Pharmacoeconomic Principles and Methods: An Introduction for Hospital Pharmacists. Hospital Pharmacy, 29, 774.

[15] Rezak, A., Abbas, H.M., Ajemian, M.S., Dudrick, S.J. and Kwasnik, E.M. (2011) Decreased Use of Computed Tomography with a Modified Clinical Scoring System in Diagnosis of Pediatric Acute Appendicitis. Archives of Surgery, 146, 64-67. http://dx.doi.org/10.1001/archsurg.2010.297 


\section{Submit or recommend next manuscript to SCIRP and we will provide best service for you:}

Accepting pre-submission inquiries through Email, Facebook, Linkedin, Twitter, etc A wide selection of journals (inclusive of 9 subjects, more than 200 journals)

Providing a 24-hour high-quality service

User-friendly online submission system

Fair and swift peer-review system

Efficient typesetting and proofreading procedure

Display of the result of downloads and visits, as well as the number of cited articles

Maximum dissemination of your research work

Submit your manuscript at: http://papersubmission.scirp.org/ 